\title{
The Relationship between Attention and Consciousness
}

\author{
Mohammad Reza Ahmadi \\ Islamic Azad University of Rasht, Iran \\ Email: mr.ahmadi2720@yahoo.com \\ Abbas Pourhossein Gilakjani \\ Islamic Azad University of Lahijan, Iran \\ Email: abbas.pouhossein@yahoo.com \\ Seyedeh Masoumeh Ahmadi \\ Islamic Azad University of Lahijan, Iran \\ Email: s_m_a57@yahoo.com
}

\begin{abstract}
The relationship between attention and consciousness is a matter of importance and of intense debate among scholars. Many psychologists and brain scientists try to link these two brain processes to each other. This article summarizes the general views concerning the issue. Many psychologists and brain scientists say that top-down selective attention and consciousness can be manipulated independently. The controversies over these two brain processes are as follows: a. One can become conscious of objects or events without attending to them. b. One can attend to objects or events without becoming conscious of them. c. Top-down attention and consciousness are completely different from each other and have the opposite effects. The paper focuses on five main issues. First, it discusses the functions of consciousness. Second, it reviews the functions of attention. Third, ways of processing visual events and behaviors are reviewed. Fourth, independent manipulation of attention and consciousness are discussed. Fifth, opposite effects of attention and consciousness will be discussed. Findings based on the review of the literature indicate that although the two psychological processes- attention and consciousness- may be linked with each other, they have distinct functions.
\end{abstract}

Index Terms - attention, consciousness, function, brain

\section{INTRODUCTION}

The two aspects of brain processes, selective attention and consciousness, are intimately connected. Scholars say that we are conscious of what we attend to. But when we withdraw attention from an event or object, we lose consciousness of its attributes and properties. What reaches visual awareness is usually the result of an attentional step. That is, awareness and attention are intimately bound together. Although the results of attention are postulated to reach consciousness, the attentional mechanisms themselves are probably largely unconscious (Crick \& Koch, 2003). More recently, some authors argue that attention and consciousness are distinct processes (Iwasaki, 1993; Hard castle, 1997; Crick \& Koch 2003; Naccache et al., 2002; Lamme, 2003; Kentridge et al., 2004; Bachman, 2006; Dehaene et al., 2006). This leaves the question of the causal relationship among these two open. Does consciousness require attention? On the contrary, good evidence shows that without attention, consciousness cannot occur (Dehaene, Changeux, Neccache, Sackur \& Sergent, 2006). Consciousness examines conceptual grounds (Block, 2005), ontological grounds (Chalmers, 1996), and psychological grounds (Tulving, 1993). Attention examines filtering, anterior and posterior brain circuits, bottom up exogenous and top-down endogenous factors (Posner \& Peterson, 1990). There is a dissociation between attention and consciousness based on the recent psychological evidence. The evidences are the following:

a. An object or event can be attended to without being consciously perceived.

b. An object or event can be consciously perceived in the near absence of attentional processing.

c. Top down attention and consciousness can have opposing effects.

\section{FUNCTIONAL ROLES FOR ATTENTION AND CONSCIOUSNESS}

According to James 'Everyone knows what attention is. It is the taking possession by the mind, in clear and vivid form, of one out of what seem several simultaneously possible objects or trains of thought. Focalization, concentration, of consciousness are of its essence. It implies withdrawal from some things in order to deal effectively with others' (James, 1890). According to many authors, including James, attention as a cognitive faculty is essential for consciousness. For instance, Zeman writes that 'attention is the sentry at the gate of consciousness' (Zeman, 2001). Others hold that 'there is no conscious perception without attention' (Mack and Rock, 1998). Another claim following 
this line of thought is that 'what is at the focus of our attention enters our consciousness, what is outside the focus of attention remains preconscious or unconscious' (Velmans, 2000). A number of other scholars point out that consciousness and attention, though closely connected, are nonetheless separate processes of the brain (Baars, 1997; Koch \& Tsuchiya, 2006). Claims such as 'awareness is a product of attention mechanism' (Lycan, 1996) and 'attention is not sufficient for consciousness and is not the same as consciousness' (Damasio, 1999) can provide support to the opinion that, pace William James, "no one [really] knows what attention is, and ... there may even not be an "it" there to be known about' (Pashler, 1998).

There is a degree of agreement on the idea that attention is a mechanism that selects relevant information from our sense data. In other words, 'the concept of attention refers to one of the basic characteristics of cognition, namely the capacity to voluntary and involuntary give priority to some parts of the information that is available at a given moment' (Naghavi \& Nyberg, 2005). As a cognitive function, attention has the remarkable property of being either voluntary or involuntary. This is of crucial importance, because it allows to distinguish between a top-down attention and a bottomup attention. The former stems from endogenous factors - that is, a degree of control by the conscious mind in order to point at a particular feature (feature-based attention), object (object-based attention) or region in space (focal attention). On the other hand, bottom-up attention is exerted by exogenous factors - that is, stimuli with a certain degree of intensity that fleetingly attract one person's focus.

Consciousness is connected with both kinds of attention. In most cases it is true that bottom-up attention represents the gate for consciousness. It is true that top-down attention occurs in the presence of awareness status. A few recent experiments (Koch \& Tsuchiya, 2006) have convincingly put forward that attention and consciousness can be related to distinct activities of the brain. Most of the time we are conscious of the world that surrounds us but without paying specifically attention to its discrete elements. Top-down attention is excluded in perceiving the gist of a scene even if we are generally conscious of it. On the other hand, blind-sight experiments with subject who have lesions in the visual areas occipital cortex support the idea that both top-down attention and bottom-up attention can occur without conscious perception. For instance, 'the blind-sight patient GY has the usual reaction-time advantages for the detection of targets in his blind visual field when attentionally cued, even when the cues are located in his blind field' (Kentridge et al., 2004). In other experiments with normal subjects, 'priming has been elicited for invisible words, but only if the subject was attending to the invisible prime-target pair; without attention, the same word fails to elicit priming' (Koch $\&$ Tsuchiya, 2006). These results suggest that the functional roles of consciousness and attention are different. Consciousness seems to be a global process capable to elaborate information in order to give a survey of what is going on inside and outside the body, whereas attention seems to be the capacity of mental states to shift and appreciate the sensory relevance or salience from one perception to another. This difference is expected to reflect into distinct neural correlates for consciousness and attention.

\section{WAyS OF PROCESSING VISUAL EVENTS AND BEHAVIOURS}

There are four ways of processing visual events and behaviors. They are as follows:
A. Attention with consciousness
B. Attention without consciousness
C. Consciousness in the near absence of attention
We try to review evidence that supports them.

\section{A. Attention with Consciousness}

Posner (1994) compares some features of attention with some features of subjective conscious experience. Consider the principle of relative amplification, according to which 'attention to sensory information amplifies brain areas used to process that modality'. He compares this feature of visual orienting with what he calls 'focal awareness': the kind of subjective recognition one has when a target pops out in a search task. He says that attention's sensory amplification correlates with focal awareness. When we perceive something, attention makes the stimulus available to working memory by allowing perceptual representations to broadcast to working memory centers. Once noticed, a stimulus can trigger responses in centers associated with executive control of attention, and this can exert top-down control on perceptual pathways, heightening sensitivity and resulting in increased stimulus contrast, both at the neural and phenomenological levels (Di Russo et al., 2001).

Evidence for a tight link between attention and consciousness comes from research showing that without attention consciousness fails. For example, even a very salient object, presented for a few seconds, sometimes goes unnoticed if it is not properly attended: inattentional blindness (Wolfe et al., 2005). Similarly, when a target stimulus draws attention, another target that rapidly follows it in temporal succession is unlikely to be seen: attentional blink (Chun \&Potter, 1995). Also, a major change between two subsequent images may go unnoticed if attention is not focused on the change: change blindness (Tse, 2004). Visual sensitivity decreases when attention is distracted: load-induced blindness (Macdonald \& Lavie, 2008). Furthermore, damages to various parts of the cortex, including frontal and parietal regions and the temporo-parietal junction (Vallar, 2007), and subcortical areas such as the pulvinar, result in invisibility of stimuli in one hemifield, in particular when there is an competing object in the other hemifield: visual neglect (Driver, 
1998). These studies show that when attention is not appropriately directed to an object, its conscious report can fail, supporting the view that attention and awareness are tightly linked.

In most of these studies the stimuli are actually perceived, only not in fine detail. When sensitivity is empirically measured under attended and unattended conditions for identical visual inputs, several studies showed nearly no change in detection thresholds (Morrone et al., 2002; Tsuchiya \& Braun, 2007). Detection of an isolated object is rarely affected by attention (Braun \& Julesz, 1998). Sometimes a relatively large stimulus or change can go unnoticed when attention is not properly directed. We believe this is because subjects do perceive the gist of the image correctly, interfering detection of a less meaningful change in the scene as if it was filled in by the gist. When a stimulus or image change is related to the gist of the scene, attention-related blindness rarely occurs. For example, when natural images are abruptly and totally unexpectedly flashed, inattentional blindness was not observed. That is, subjects can describe the gist of these photos (Mack \& Rock, 1998). Similarly, the attentional blink decreases when two subsequent target stimuli differ in their gist compared to when they contain the same gist (Evans \& Treisman, 2005; Einhäuser et al., 2007). The case of change blindness is perhaps most telling. A most effective demonstration of change blindness utilizes two photographs with an identical gist (e.g., soldiers near an airplane) with a change that does not modify the gist (e.g., airplane with or without an engine). However, if one uses a minor change that alters the gist between two images (for example, "a log immediately in the path of a man kayaking down a river was changed into another kayak," Sampanes et al., 2008), observers notice the change much faster than when the gist did not change (e.g., the log was replaced by a rock) (Sampanes et al., 2008). It can be concluded that attentional reduction does not usually result in invisibility of an isolated object and that a large change can be missed as long as it does not alter the gist of the scene. Attention and consciousness may not be coupled as tightly as has been thought even in the above cases.

\section{B. Attention without Consciousness}

Can observers deploy attention to a stimulus that is not accessible to consciousness? The answer now seems quite definitely: yes, they can. The evidence comes from (1) the attentional manipulation of non-conscious priming and adaptation and (2) the effects of invisible stimuli on attentional cueing. Behavioral (Sumner et al., 2006; Kentridge et al., 2008; Finkbeiner \& Palermo, 2009; Tapia et al., 2010; Van den Bussche et al., 2010) and neuronal (Kiefer \& Brendel, 2006) non-conscious priming is enhanced by spatial (Kentridge et al., 2008; Finkbeiner and Palermo, 2009; Van den Bussche et al., 2010), feature-based (Melcher et al., 2005; Tapia et al., 2010), or temporal (i.e., cueing when the prime or targets appear) (Naccache et al., 2002) attention. So far, there is no evidence that object-based attention can give rise to non-conscious priming (Tapia et al., 2010). Likewise, the strength of adaptation to perceptually invisible (attributes of) stimuli such as orientation (Kanai et al., 2006; Bahrami et al., 2008a; Shin et al., 2009) or the gender of faces (Shin et al., 2009) is increased by enhancing spatial and feature-based attention to these features. When the invisible orientation is defined by illusory contours, spatial attention is even necessary for adaptation (Montaser-Kouhsari \& Rajimehr, 2004).

Kentridge et al., (2004) studied on G.Y., who suffered from blind-sight G.Y. was asked to show whether a target had been presented somewhere in his blind field. On some trials a cue was presented in the blind field just before the target, which either accurately or inaccurately forecast the target location. When the cue was accurate, G.Y. was faster and made fewer errors. They conclude that he is attending in his blind field, and therefore attention can occur without consciousness.

The existence of attentional deployment without conscious registration of a stimulus is also supported by studies that showed attentional cueing effects on sub-threshold or invisible stimuli (Jiang et al., 2006; Sato et al., 2007; Lin et al., 2009; Meteyard et al., 2008; Bauer et al., 2009). Tsushima et al. (2006) even showed that random dot motion stimuli, whose coherency is so low that subjects cannot discriminate their motion direction above chance, are more distracting and detrimental for a concurrently performed central task than motion stimuli with high coherency. Using fMRI, it was shown that compared to supra-threshold motion, sub-threshold motion evokes stronger hemodynamic activation in the motion sensitive cortical area, MT, because the weak sensory stimulus does not activate an area in lateral prefrontal cortex (LPFC) that is presumed to be responsible for inhibiting distracting motion-related activity in MT. These studies demonstrate attention can be directed toward and away from a stimulus or one of its attributes without that stimulus or attribute ever being visible.

\section{Consciousness in the Near Absence of Attention}

Lamme (2003) conducted the following blindness experiment. Subjects were presented, for $500 \mathrm{ms,} \mathrm{with} \mathrm{a} \mathrm{stimulus}$ consisting of multiple items arranged in a circle. Then a gray screen was displayed for 200-1500 ms, after which the same array as in stimulus 1 was presented, except that in this one an item was changed (Stimulus 2). The changed item was cued with an orange bar, and subjects were asked whether the cued item had changed or not. Subjects performed poorly $(60 \%$ correct). But when the item was cued in advance during the display of stimulus 1 , they performed quite well $(100 \%)$. When the cue was shown alone in the gray screen that appeared after stimulus 1 , they performed as good as they did when the cue was presented during stimulus $1(88 \%)$.

This indicates that all of the items in stimulus 1 are conscious and remain in consciousness even after the stimulus is removed, until they are overwritten by stimulus 2 . And this also shows that each item is conscious before it is cued, thus, attention is necessary for consciousness. To some, consciousness in the complete absence of attention, is an obvious 
fact because we can always perceive stimuli in the periphery, outside the focus of attention. Dual- task paradigms experimentally support this idea: non - trivial tasks, such as scene categorization (Li et al., 2002), gender discrimination (Reddy et al., 2004), and face identification (Reddy et al., 2006) can be performed in the "near absence" of attention.

If there is attention without consciousness, one can ask whether or not there exists consciousness without attention. Can a subject be conscious of an object or of an attribute of an object without attending to the object or its attribute? We focus on evidence in favor of that view obtained with the dual-task paradigm. Other lines of evidence, including popout, iconic memory, and partial reportability, have been reviewed extensively elsewhere (Block, 2007; Koch \& Tsuchiya, 2007; Lamme, 2010). Top-down attention is employed when there is competition among two or more nearby objects (Desimone \& Duncan, 1995). In fact, almost all the neurophysiological studies of visual attention employ stimulus configurations that engender competition of resources by placing two objects within a receptive field of a recorded neuron. Without competition, that is when a single stimulus is presented in an otherwise empty field, it is very difficult to observe any top-down attentional modulation (Reynolds \& Chelazzi, 2004). At the perceptual level, if a display contains only a single object in isolation, subjects become aware of it in any attentional state. This simple fact seems to undermine the argument that top-down attentional amplification from the frontal area is always necessary for consciousness (Dehaene et al., 2006)

When there is competition among objects, top-down attention exerts a major gating role for consciousness, yet not all the aspects of vision are affected equally. In the dual-task paradigm, spatial attention is focused at fixation by a demanding task, while performance is measured on a simultaneously presented peripheral stimulus. Dual task studies have shown that simple detection and discrimination of a stimulus in a pop-out array is not compromised when attention is drawn away (Braun \& Sagi, 1990; Braun \&Julesz, 1998). The gist of a natural scene picture as well as gender and identity of a face can be perceived under dual-task conditions (Fei-Fei et al., 2002; Reddy et al., 2006, Torralba et al., 2006). What is considered a change in gist and what not, seems to be affected by expertise (Werner \& Thies, 2000). This suggests that consciousness without attention develops in response to extensive experience with a particular class of images. Discrimination of other stimuli - for example, discriminating an arbitrarily rotated letter "L" from an arbitrarily rotated letter "T" - is severely affected when spatial attention is soaked up by the central task. While it cannot be guaranteed that observers deploy no top-down attention what-so-ever to the peripheral stimulus in these dualtasks experiments, these experiments do show that subjects can perform certain discriminations but not others in the near absence of top-down attention. Without top-down attention, observers cannot report the details of a scene even though they may erroneously claim to have seen a certain stimulus with high confidence (de Gardelle et al., 2009). Yet, observers often do perceive the gist of the scene and can accurately perceive the category of the object (whether it is a face, a natural scene, a letter, etc.). Even with a mere $30 \mathrm{~ms}$ exposure to natural scenes, followed by a mask, observers can clearly perceive their gist (Fei-Fei et al., 2002) even in the absence of any expectation about what type of scene will be flashed. Within these $30 \mathrm{~ms}$, top-down attentional bias could not have taken effect.

\section{INDEPENDENT MANIPULATION OF ATTENTION AND CONSCIOUSNESS}

Van den Bussche et al., (2010) examined the magnitude of priming effects by independently manipulating prime visibility and spatial attention, leading to a full factorial $2 \times 2$ design. The prime could signal the same behavioral response as the subsequent stimulus (a congruent trial) or an opposite behavioral response (an incongruent trial). When the prime was invisible and unattended, no priming effects were found. Compared to this baseline condition, both attention and awareness increased the priming effects. However, each manipulation contributed to the priming effects in distinct ways: when attention was directed to the invisible prime, the reaction times for the congruent trials were speeded compared to neutral trials, while when visibility was increased for the unattended prime, the reaction times for the incongruent trials were slowed down compared to the neutral condition. In other words, attention to invisible stimuli and visibility of unattended stimuli both enhanced the priming effects, but via distinctive neuronal mechanisms. In visible and attended conditions, both the speeding up of congruent trials and the slowing down of incongruent trials occurred.

Kanai et al. (2006) investigated the magnitude of the tilt after effect by independently manipulating attention and consciousness. Attention showed an interesting effect. While feature-based attention increased the size of the after effect regardless of the visibility of the adaptor, spatial attention did so only when the adapting stimulus was visible. While later studies showed that spatial attention could modulate the tilt after effect (Bahrami et al., 2008a) it is still important to know whether different kinds of attention (spatial, feature-based, and object-based) act on visible and invisible stimuli with different sensitivity. As to conscious perception, it had a similar influence as attention, increasing the strength of the after effect. Wyart \& Tallon-Baudry (2008) utilized MEG to dissociate neuronal correlates of attention and consciousness. They showed subjects a faint stimulus, which was visible in roughly half of the trials. They manipulated spatial attention by an endogenous cue. In a time-frequency analyses of MEG power, mid-frequency (54$64 \mathrm{~Hz}$ ) gamma activity was correlated with stimulus visibility for a sustained period, from 250 to $500 \mathrm{~ms}$, in occipital sensors, contra-lateral to the stimulus. Independent of this awareness related activity, high-frequency (76-90 Hz) gamma activity was correlated with attention slightly later, for 350-500 ms in parietal sensors. These effects did not interact with each other and suggest that attention and consciousness may have dissociable neuronal correlates. 


\section{ATtENTION AND CONSCIOUSNESS OpPOSE EACH OTHER}

One of the most striking pieces of evidence for distinctive neuronal processes for attention and consciousness comes from the studies of afterimages. Afterimages were long thought to have their sole origin in the retina (Loomis, 1978; Sakitt, 1976; Virsu \& Laurinen, 1977; Wilson, 1997), which is impervious to attention and awareness-related signals (in mammals, there are no central fibers that project back into the retina). However, there is now increasing evidence that cortical sites also play an important role in afterimage formation (Gilroy \& Blake, 2005; Tsuchiya \& Koch, 2005); for example, removing stimuli from awareness by inter-ocular suppression decreases afterimage duration and strength (Gilroy \& Blake, 2005; Tsuchiya \& Koch, 2005). Attentional withdrawal increases afterimage durations (Wede \& Francis, 2007; Lak, 2008). This is quite counterintuitive because attention is thought to boost neuronal activity (Reynolds \& Heeger, 2009), which would result in stronger adaptation (Ling \& Carrasco, 2006), leading to longer afterimages.

Afterimages, low spatial frequency target detection and implicit learning are potential examples where attention impairs performance while conscious awareness of the stimuli improves the performance. Oliver \& Nieuwenhuis (2005) found that observers report the second of two rapidly presented stimuli more often when they are distracted by an another task than when they are concentrated on the display. This shows that a reduction of attention can be accompanied by an increase in awareness of the target. This striking demonstration may reflect different attentional networks. The attentional blink arises because while the person concentrates on target 1 and as a consequence target 1 and target 2 are not perceived as separate events. The dramatic dissociation between awareness of a target and the availability of attention provides evidence that the two phenomena are not exactly the same. This dissociation may arise because there is a specific inhibition to processing a second target when it is similar to a first target which is still being attended. If concentration of the first target is reduced by a second task the inhibition may be released. If the second target is inhibited when the first is being processed, the reported dissociation may not show that attention is distinct from awareness, but instead that attention may be distinct from performance.

It is essential that the effects of attention and consciousness be studied using identical stimuli and tasks. For example, stimulus parameters, such as the spatial frequency of the adaptor, are critical in determining the afterimage strength (Brascamp et al., 2010). Specifically, the decrease in afterimage duration with decreased visibility only occurs for low spatial frequency stimuli. For high-spatial frequency stimuli, a paradoxical increase in afterimage duration occurs with decreased visibility (Brascamp et al., 2010). These differences make previous research difficult to compare. A recent study (van Boxtel et al., 2010) addressed the separate influences of attention and awareness on afterimage perception, employing a full-factorial design while controlling stimulus and task confounds. Attention and awareness were independently manipulated during the afterimage induction phase, while the effects of these manipulations were measured in the afterimage perception phase. Attention to the afterimage inducer was manipulated by employing an attention-distracting task at fixation (i.e., the central task). This task could be easy or hard (Bahrami et al., 2008b; Macdonald \& Lavie, 2008), ensuring identical visual input while manipulating the levels of attention available to the afterimage inducer. The conscious visibility of the inducer stimulus was manipulated independently of attention by means of continuous flash suppression, a form of inter-ocular suppression (i.e., presenting a very salient object in one eye that completely suppresses the afterimage inducer in the other eye (Tsuchiya \& Koch, 2005; Gilroy \& Blake, 2005; Tsuchiya et al., 2006). With the suppression present, the Gabor patch inducing the afterimage was not perceived. This 2 $\square 2$ design allowed for a full-factorial comparison (i.e., high attention/visible, low attention/visible, high attention/invisible, and low attention/invisible).

van Boxtel et al., (2010) found that attention decreased the duration of the afterimage while awareness increased the duration of the afterimage. In other words: the effects of attention and awareness opposed each other at the level of perception. There was no interaction between the effects of attention and consciousness. In a related study, the effects of attention and consciousness on afterimages were investigated over a range of spatial frequencies (Brascamp et al., 2010). Using signal detection theory, these authors showed that the difference between the effects of attention and awareness can be pinned down to the different manner in which attention and awareness influence different visual channels. Briefly, afterimage duration is determined by the strength of adaptation of both phase-sensitive and phase-insensitive visual channels (Wede \& Francis, 2007; Francis, 2010). The afterimage appears stronger when the adaptation of phasesensitive channels is increased, because afterimages originate from this adaptation. In contrast, when adaptation in phase-insensitive channels is increased the afterimage looks weaker, because this adaptation increases detection thresholds, thus making the afterimage harder to see (Leguire \& Blake, 1982; Georgeson \& Turner, 1985). Brascamp and colleagues showed that attention and consciousness increased adaptation in both channels, and that afterimage durations reflect the balance between these two factors. The observed opposite effects of afterimage durations at the perceptual level are caused by a change in balance between both channels (due to adaptation), rather than being due to opposite effects at an early neural level. The adaptation effects of attention and consciousness were correlated for phase- insensitive adaptation, while they were uncorrelated for phase-sensitive adaptation (Brascamp et al., 2010).

\section{CONCLUSION}


Functional considerations and the empirical and conceptual work of many scholars indicate that the two psychological processes- attention and consciousness- are distinct neuronal processes with distinct functions. Although these two psychological defined processes may be linked with each other, they are not the same. The issues of selection and control central to the study of attention are important aspects of most theories of consciousness. The study of attention has implicated a cortical network used for orienting that has many similarities to the awareness system as a model for the study of consciousness. We find that there exists considerable evidence for attentional deployment without consciousness, supporting the view that attention is not sufficient for consciousness. We also reviewed evidence for consciousness without attention, which indicates that attention is not necessary for consciousness. Yet many scholars find the evidence for this latter claim insufficiently compelling. We believe that psychophysical studies are not powerful enough to decide this question. In particular, it may never be possible to fully prevent subjects paying some attention to a stimulus on the basis of purely behavioural techniques. Many assume that an important means by which top-down attention influence sensory processing is via cortico-cortical feedback connections (Macknik \& MartinezConde, 2007). It may be possible to transiently, delicately, reversibly and specifically knock out all top-down corticocortical pathways, thereby preventing the subject, most likely a mouse or non-human primate, from exerting any sort of top-down attentional control. This could be achieved via molecular-biology tools, in particular opto-genetics (Han et al., 2009; Gradinaru et al., 2010). Unbraiding the complex relationship between attention and consciousness will ultimately depend on such powerful, interventionist tools. Whether the progress in studies of attention and brain mechanisms will provide a complete analysis of consciousness or whether fundamentally new mechanisms will be needed is a matter of opinion, but what seems clear is that there has been very considerable recent progress toward understanding brain networks relevant to the processes of attention and consciousness and the tools are present for considerable future development.

\section{ACKNOWLEDGEMENTS}

We thank Alizadeh, Babaee, and Khazaee for their extensive and insightful discussions.

\section{REFERENCES}

[1] Baars, B. (1997). In the Theater of consciousness: The Workspace of the Mind. New York, Ny: Oxford University Press. 2001 reprint: ISBN 978-19-514703-2.

[2] Bachman, T. (2006). A single Mata theoretical framework for a number of conscious vision phenomena. In psychological Science around the World, pp. 229-242, psychology press.

[3] Bahrami, B., Carmel, D., Walsh, V., Rees, G., \& Lavie, N. (2008a). Spatial attention can modulate unconscious orientation processing. Perception 37, 1520-1528.

[4] Bahrami, B., Carmel, D., Walsh, V., Rees, G., \& Lavie, N. (2008b). Unconscious orientation processing depends on perceptual load. J. Vis. 8, 1-10.

[5] Barras, B. J. (1997). Some essential difference between consciousness and attention, perception and working memory. Conscious Cogn. 6, 363-371.

[6] Bauer, F., Cheadle, S. W., Parton, A., Muller, H. J., \& Usher, M. (2009). Gamma flicker triggers attentional selection without awareness. Proc. Natl. Acad.Sci. U.S.A. 106, 1666-1671.

[7] Block, N. (2007). Consciousness, accessibility, and the mesh between psychology and neuroscience. Behav. Brain Sci. 30, 481-499; discussion 499-548.

[8] Bolck, N. (2005). Two neural correlates of consciousness. Trends Cogn. Sci. 9, 46-52.

[9] Brascamp, J. W., van Boxtel, J. J., Knapen, T., \& Blake, R. (2010). A dissociation of attention and awareness in phase-sensitive but not phase-insensitive visual channels. J. Cogn. Neurosci. 22, 2326-2344.

[10] Braun, J., \& Julesz, B. (1998). Withdrawing attention at little or no cost: detection and discrimination tasks. Percept. Psychophys. 60, 1-23.

[11] Braun, J., \& Sagi, D. (1990). Vision outside the focus of attention. Percept. Psychophys. 48, 45-58.

[12] Chalmers, D. J. (1996). The Conscious Mind: in search of a fundamental theory, New York: Oxford University Press.

[13] Chun, M. M., \& Potter, M. C. (1995). A two-stage model for multiple target detection in rapid serial visual presentation. J. Exp. Psychol. Hum. Percept. Perform. 21, 109-127.

[14] Crick, F. \& Koch, C. (2003). A framework for consciousness. Nat.Neurosci.6, 119-126.

[15] Damasio, A. (1999). The Feeling of What Happens: Body and Emotion in the Making of Consciousness. New York. Harcourt Brace.p. 4.

[16] de Gardelle, V., Sackur, J., \& Kouider, S. (2009). Perceptual illusions in brief visual presentations. Conscious. Cogn. 18, 569577.

[17] Dehaene, S., \& Changeux, J. P., \& Naccache, L., \& Sackur, J., \& Sergent, C. (2006). Conscious, preconscious and subliminal processing: a testable taxonomy. Trends Cogn Sci. 10, 204-211.

[18] Desimone, R., \& Duncan, J. (1995). Neural mechanisms of selective visual attention. Annu. Rev. Neurosci. 18, $193-222$.

[19] Di Russo, F., Spinelli, D., \& Morrone, M. C. (2001). Automatic gain control contrast mechanisms are modulated by attention in humans: evidence from visual evoked potentials. Vision Res. 2001, 41, 2435-2447.

[20] Driver, J. (1998). "The neuropsychology of spatial attention," in Attention Studies in Cognition, ed. H. Pashle (Philadelphia, PA: Psychology Press). 297-340.

[21] Einhäuser, W., Koch, C., \& Makeig, S. (2007). The duration of the attentional blink in natural scenes depends on stimulus category. Vision Res. 47, 597-607. 
[22] Evans, K. K., \& Treisman, A. (2005). Perception of objects in natural scenes: is it really attention free? J.Exp. Psychol. Hum. Percept. Perform. 31, 1476-1492.

[23] Finkbeiner, M., \& Palermo, R. (2009). The role of spatial attention in nonconscious processing: a comparison of face and nonface stimuli. Psychol. Sci. 20, 42-51.

[24] Francis, G. (2010). Modeling filling-in of afterimages. Atten. Percept. Psychophys. 72, 19-22.

[25] Georgeson, M. A., and Turner, R. S. (1985). Afterimages of sinusoidal, squarewave and compound gratings. Vision Res. 25, $1709-1720$.

[26] Gilroy, L. A., \& Blake, R. (2005). The interaction between binocular rivalry and negative afterimages. Curr. Biol.15, 17401744.

[27] Gradinaru, V., Zhang, F., Ramakrishnan, C., Mattis, J., Prakash, R., Diester, I., Goshen, I., Thompson, K. R., \& Deisseroth, K. (2010). Molecular and cellular approaches for diversifying and extending optogenetics. Cell 141, 154-165.

[28] Han, X., Qian, X., Bernstein, J. G., Zhou, H. H., Franzesi, G. T., Stern, P., Bronson, R. T., Graybiel, A. M., Desimone, R., \& Boyden, E. S. (2009). Millisecondtimescale optical control of neural dynamics in the non-human primate brain. Neuron. 62, 191-198.

[29] Hardcastle, V. G. (1997). Attention versus consciousness: A distinction with a difference. Cognitive studies: Bulletin of the Japanese Cognitive Science Societ. 4, 56-66.

[30] Iwasaki, S. (1993). Spatial attention and two modes of visual consciousness. Cognition. 49, 211-233.

[31] James, W. (1890). The Principles of Psychology. New York, NY: Henry Holt and Co: 1890.

[32] Jiang, Y., Costello, P., Fang, F., Huang, M., \& He, S. (2006). A gender- and sexual orientation-dependent spatial attentional effect of invisible images. Proc. Natl. Acad. Sci. U.S.A. 103, 17048-17052.

[33] Kanai, R., Tsuchiya, N., \& Verstraten, F. A. (2006). The scope and limits of top-down attention in unconscious visual processing. Curr. Biol. 16, 2332-2336.

[34] Kentridge, R. W. et al., (2004). Spatial attention speeds discrimination without awareness in blind-sight. Neuropsychologia. 42, 831-835.

[35] Kentridge, R. W., Heywood CA, Weiskrantz L. (2004). Spatial attention speeds iscrimination without awareness in blindsight. Neuropsychologia, 42, 831-835.

[36] Koch, C., \& Tsuchiya, N. (2006). Attention and consciousness: Two distinct brain processes. Trends in Cognitive Sciences, 11, $16-22$.

[37] Lamme, V. A. (2003). Why visual attention and awareness are different. Trends Cogn Sci. 7, 12-18.

[38] Lamme, V. A. (2010). How neuroscience will change our view on consciousness. Cogn. Neurosci. 1, 204-220.

[39] Leguire, L. E., \& Blake, R. (1982). Role of threshold in afterimage visibility. J. Opt. Soc. Am. 72, 1232-1237.

[40] Li , F. F., VanRullen, R., Koch, C.,\& Perona, P. (2002). Rapid natural scene categorization in the near absence of attention. Pro Natl Acad Sci, USA, 99, 95-96-9601.

[41] Lin, J. Y., Murray, S. O., \& Boynton, G. M. (2009). Capture of attention to threatening stimuli without perceptual awareness. Curr. Biol. 19, 1118-1122.

[42] Ling, S., and Carrasco, M. (2006). When sustained attention impairs perception. Nat. Neurosci. 9, 1243-1245.

[43] Loomis, J. M. (1978). Complementary afterimages and the unequal adapting effects of steady and flickering light. J. Opt. Soc. Am. 68, 411-416.

[44] Lycan, W. G. (1996). Consciousness and experience. Cambridge, MA: MIT Press.

[45] Macdonald, J. S., \& Lavie, N. (2008). Load induced blindness. J. Exp. Psychol. Hum. Percept. Perform. 34, $1078-1091$.

[46] Mack, A., \& Rock, I. (1998). Inattentional Blindness. Cambridge, MA: MIT Press.

[47] Macknik, S. L., \& Martinez-Conde, S. (2007). The role of feedback in visual masking and visual processing. Adv. Cogn. Psychol. 3, 125-152.

[48] Melcher, D., Papathomas, T. V., \& Vidnyánszky, Z. (2005). Implicit attentional selection of visual features. Neuron 46, 723729.

[49] Meteyard, L., Zokaei, N., Bahrami, B., \& Vigliocco, G. (2008). Visual motion interferes with lexical decision on motion words. Curr. Biol. 18, R732-R733.

[50] Montaser-Kouhsari, L., \& Rajimehr, R. (2004). Attentional modulation of adaptation to illusory lines. J. Vis. 4, 434-444.

[51] Morrone, M. C., Denti, V., \& Spinelli, D. (2002). Color and luminance contrasts attract independent attention. Curr. Biol. 12 , $1134-1137$.

[52] Naccache. L., Blandin. E., \& Dehaene. (2002). Unconscious masked priming depends on temporal attention. Psychol S. 13, 416-424.

[53] Naghavi, H. R., \& Nyberg, L. (2005). Common fronto-parietal activity in attention, memory, and consciousness: Shared demands on integration? Consciousness and Cognition, 14, 390-425.

[54] Olivers , C. N., \& Nieuwenhuis, S. (2005). The beneficial effect of concurrent task- irrelevant mental activity on temporal attention. Psychol Sci. 16, 265-269.

[55] Pashler, H. (1998). The psychology of attention. Cambridge, MA: MIT Press.

[56] Posner, M. I. (1994). Attention: the mechanism of consciousness. Proc. National Acad of Sciences, U.S.A., 91, (16), 7398-7402.

[57] Posner, M. I., \& Peterson, S. E. (1990). The attention system of the brian. Annu Rev Neurosci. 13, 25-42.

[58] Reddy, L., \& Reddy, L., \& Koch, C. (2006). Face identification in the near-absence of focal attention. Vision Res. 46, 23362343.

[59] Reynolds, J. H., \& Chelazzi, L. (2004). Attentional modulation of visual processing. Annu. Rev. Neurosci. 27, 611-647.

[60] Reynolds, J. H., \& Heeger, D. J. (2009). The normalization model of attention. Neuron, 61, 168-185.

[61] Sakitt, B. (1976). Psychophysical correlates of photoreceptor activity. Vision Res. 16, 129-140.

[62] Sampanes, A. C., Tseng, P., \& Bridgeman, B. (2008). The role of gist in scene recognition. Vision Res. 48, $2275-2283$.

[63] Sato, W., Okada, T., \& Toichi, M. (2007). Attentional shift by gaze is triggered without awareness. Exp. Brain Res. 183, 87-94. 
[64] Shin, K., Stolte, M., \& Chong, S. C. (2009). The effect of spatial attention on invisible stimuli. Atten. Percept. Psychophys. 71, 1507-1513.

[65] Sperling, C. (1984). A unified theory of attention and signal detection. In R. Parasuraman \& D. R. Davies (Eds.), Varieties of attention. New York: Academic Press.

[66] Sumner, P., Tsai, P. C., Yu, K., \& Nachev, P. (2006). Attentional modulation of sensorimotor processes in the absence of perceptual awareness. Proc. Natl. Acad. Sci. U.S.A. 103, 10520-10525.

[67] Swan, L. (2001). Unilateral spatial neglect. Phys. Ther. 81, 1572-1580.

[68] Tapia, E., Breitmeyer, B. G., \& Shooner, C. R. (2010). Role of task-directed attention in non-conscious and conscious response priming by form and color. J. Exp. Psychol. Hum. Percept. Perform. 36, 74-87.

[69] Torralba, A., Oliva, A., Castelhano, M. S., \& Henderson, J. M. (2006). Contextual guidance of eye movements and attention in real-world scenes: the role of global features on object search. Psychol. Rev. 4, 766-786.

[70] Tse, P. U. (2004). Mapping visual attention with change blindness: new directions for a new method. Cogn. Sci. 28, 241-258.

[71] Tsuchiya, N., \& Braun, J. (2007). Contrast thresholds for component motion with full and poor attention. J. Vis. 7, 1.

[72] Tsuchiya, N., \& Koch, C. (2005). Continuous flash suppression reduces negative afterimages. Nat. Neurosci. 8, $1096-1101$.

[73] Tsuchiya, N., \& Koch, C. (2008a). Attention and consciousness. Scholarpedia , 3, 4173.

[74] Tsuchiya, N., Koch, C., Gilroy, L. A., \& Blake, R. (2006). Depth of interocular suppression associated with continuous flash suppression, flash suppression, and binocular rivalry. J. Vis. 6, 1068-1078.

[75] Tsushima, Y., Sasaki, Y., \& Watanabe, T. (2006). Greater disruption due to failure of inhibitory control on an ambiguous distractor. Science. 314, 1786-1788.

[76] Tulving, E. (1993). Varieties of consciousness and levels of awareness in memory. In attention: Selection, Awareness and Control. A Tribute to Donald Broadbent, A. Braddelely and L. Wiskrantz ed. Oxford University Press pp, 583-299.

[77] Vallar, G. (2007). Spatial neglect, Balint-Homes' and Gerstmann's syndrome, and other spatial disorders. CNS Spectr. 12, $527-$ 536.

[78] van Boxtel, J. J. A., Tsuchiya, N., \& Koch, C. (2010). Opposing effects of attention and consciousness on afterimages. Proc. Natl. Acad. Sci. U.S.A. 107, 8883-8888.

[79] Van den Bussche, E., Hughes, G., Humbeeck, N. V., \& Reynvoet, B. (2010). The relation between consciousness and attention: an empirical study using the priming paradigm. Conscious. Cogn. 19, 86-97.

[80] Velmans, M. (2000). Understanding consciousness. London: Routledge.

[81] Virsu, V., and Laurinen, P. (1977). Longlasting afterimages caused by neural adaptation. Vision Res. 17, 853-860.

[82] Wede, J., \& Francis, G. (2007). Attentional effects on afterimages: theory and data. Vision Res. 47, 2249-2258.

[83] Werner, S., \&Thies, B. (2000). Is "change blindness" attenuated by domain-specific expertise? An expert-novices comparison of change detection in football images. Vis. cogn. 1, 163-173.

[84] Wilson, H. R. (1997). A neural model of foveal light adaptation and afterimage formation. Vis. Neurosci. 14, 403-423.

[85] Wyart, V., \& Tallon-Baudry, C. (2008). Neural dissociation between visual awareness and spatial attention. J. Neurosci. 28, $2667-2679$.

[86] Zeman, A. (2001). Consciousness. Brain, 124, 1263-1289.

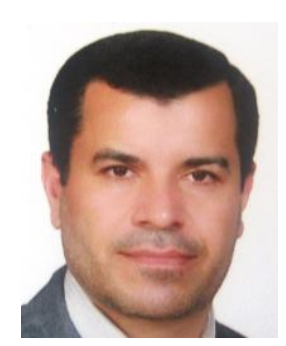

Mohammad Reza Ahmadi is a Ph.D. student of SLL at Universiti Sains Malaysia, Malaysia. He received his M.A. in English Language Teaching (ELT) from Islamic Azad University of Garmsar, Iran. His main interests include listening skill and motivation.

Abbas Pourhosein Gilakjani is a Ph.D. student of SLL at Universiti Sains Malaysia, Malaysia. He is also a faculty member of English Translation Department at Islamic Azad University of Lahijan, Iran. He has taught English courses for over 11 years at 3 open universities in Guilan, Iran.

Seyedeh Masoumeh Ahmadi received her B.A. degree from Islamic Azad University of Lahijan, Iran. She will start her education in M.A. in Computer Network at Universiti Sains Malaysia, Malaysia 5 months later. 